\title{
Fuzzy logic principles for an induction motor direct torque control application
}

\author{
Dmitry Olkhovatov ${ }^{1 *}$, Vladimir Noskov ${ }^{1}$, and Tatiana Ripol-Saragosi ${ }^{1}$ \\ ${ }^{1}$ Rostov State Transport University, Rostov-on-Don, Russian Federation
}

\begin{abstract}
In the article three induction engine torque direct control system designing methods are compared: classical; width-pulse voltage modulation is set according to the output of "Switching table" block; based on fuzzy logic mathematical apparatus. The direct torque control systems structure and particular blocks included in are considered. Numerical methods in order to determine the harmonic composition of such values as the electromagnetic torque, the stator coil voltage and current at low rotor rotation speeds are described. The obtained results analysis is given.
\end{abstract}

\section{Introduction}

The widespread use of squirrel cage induction motors (IM) based on frequency controlled electric engines is due IM low cost, simplicity of design, low maintenance costs and a wellestablished production. The rapid development of new methods of IM control is associated with the microprocessor and semiconductor power electronics technologies growth, making capable implementation much more complex algorithms.

The most common for IM is vector control. These are systems of subordinate regulation of a controlled coordinate, which is the stator current. They provide high quality control, but require an exact knowledge of the motor parameters, which can change during operation or are unknown at all $[1,2]$.

An alternative method may be direct torque control (DTC), which principles first were proposed by Takahashi and Noguchi in 1985 [3]. This method does not require the current loop and pulse-width modulation (PWM). The autonomous inverter output voltage (OVI) vector selection based on the error signs of the controlled values (the stator flux linkage and electromagnetic torque) and the OVI vector instant position. The method has a number of advantages: high operation speed, implementation simplicity and low sensitivity to changes of engine parameters.

DTC electric drives [4] are perspective as auxiliary mechanisms for locomotives. Now, there are two main directions for DTC further development: 1) using a matrix converter that allows the OVI amount increasing [5]; 2) using the fuzzy sets theory in the OVI definition process $[6,7]$. Both methods mainly aimed to torque fluctuation reduction.

\footnotetext{
* Corresponding author: olkhovatovdmitry@gmail.com
} 


\section{Classical DTC system}

The DTC systems operation is based on the IM electromagnetic torque equation [8]:

$$
m_{e}=\frac{3}{2} z p \frac{k_{1} \cdot k_{2}}{\sigma L_{m}}\left|\psi_{S} \times \psi_{R}\right|=\frac{3}{2} z p \frac{k_{1} \cdot k_{2}}{\sigma L_{m}} \psi_{S m} \cdot \psi_{R m} \cdot \sin \vartheta
$$

At Figure 1 the classical DTC system model, designed in Matlab, is given.

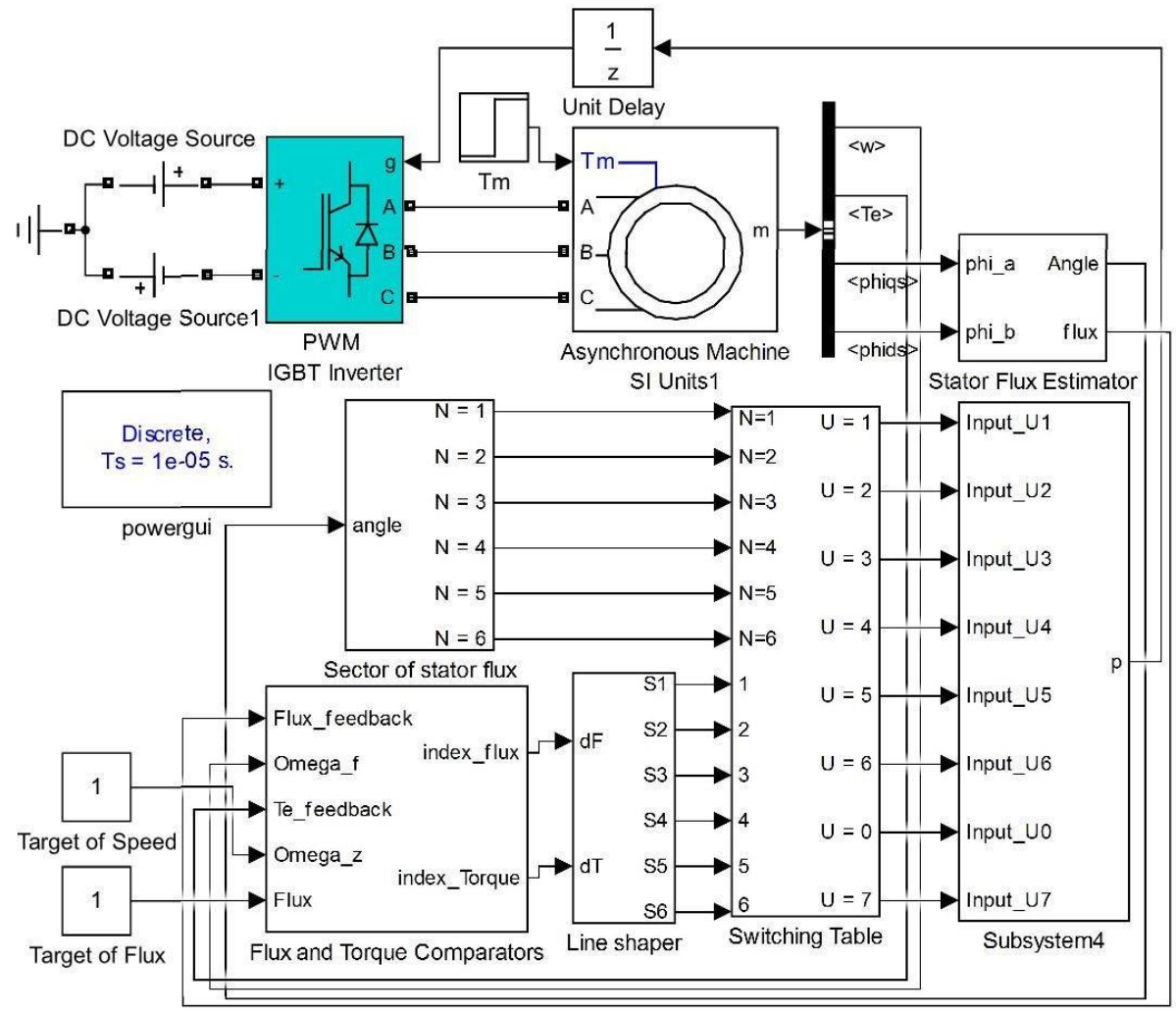

Fig. 1. Classical DTC model.

The following blocks form the classical DTC system.

The «Sector of stator flux» block defines the sector of the stator flux linkage vector location (see Figure 2). The sector sets a column in the table for selecting the resultant autonomous inverter voltage vector (RV) (see Table 1). 


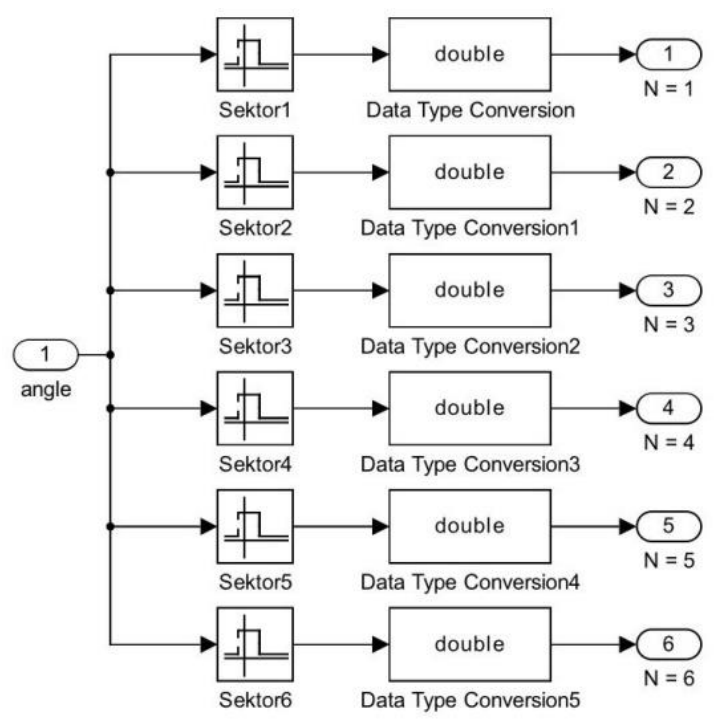

Fig. 2. Block Sector of stator flux.

Table 1. OVI switching table.

\begin{tabular}{|c|c|c|c|c|c|c|c|}
\hline$\Delta \psi_{S}$ & $\Delta T_{e}$ & Sector1 & Sector2 & Sector3 & Sector4 & Sector5 & Sector6 \\
\hline \multirow{3}{*}{1} & 1 & $V 2$ & $V 3$ & $V 4$ & $V 5$ & $V 6$ & $V 1$ \\
\cline { 2 - 8 } & 0 & $V 7$ & $V 0$ & $V 7$ & $V 0$ & $V 7$ & $V 0$ \\
\cline { 2 - 8 } & -1 & $V 6$ & $V 1$ & $V 2$ & $V 3$ & $V 4$ & $V 5$ \\
\hline \multirow{3}{*}{0} & 1 & $V 3$ & $V 4$ & $V 5$ & $V 6$ & $V 1$ & $V 2$ \\
\cline { 2 - 8 } & 0 & $V 0$ & $V 7$ & $V 0$ & $V 7$ & $V 0$ & $V 7$ \\
\cline { 2 - 8 } & -1 & $V 5$ & $V 6$ & $V 1$ & $V 2$ & $V 3$ & $V 4$ \\
\hline
\end{tabular}

«Flux and Torque Comparators» is the block of regulators, which realize the reference and feedback speed and flux signals comparison. The block consists of a proportionalintegral (PI) controller of the speed. Its output signal is limited by the Saturation block. Further, the limited signal from the PI controller compares with the feedback torque signal. The flux error signal goes to a two-position relay controller (RC), and the torque difference signal - to a three-position RC. It consists of two parallel-connected two-position RC (see Figure 3). The inputs of the Line shaper block receive the output signals of flux and torque RC. This block, depending on the torque $\left(\Delta \mathrm{T}_{\mathrm{e}}=-1 ; \Delta \mathrm{T}_{\mathrm{e}}=0 ; \Delta \mathrm{T}_{\mathrm{e}}=1\right)$ and stator flux value $\left(\Delta \Psi_{\mathrm{s}}=1 ; \Delta \Psi_{\mathrm{s}}=0\right)$ generates a signal corresponding to the line in the Switching Table 1.

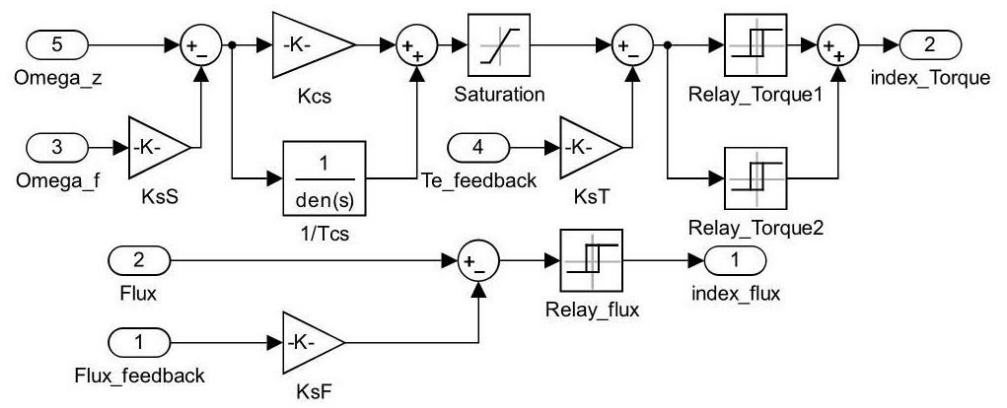

Fig. 3. Block «Flux and Torque Comparators». 
«Stator Flux Estimator» is the block that calculates the absolute value and the position of the stator flux linkage vector. The equations describing the block operation:

$$
\begin{aligned}
& \psi_{S m}=\left|\psi_{s \alpha}^{2}+\psi_{s \beta}^{2}\right| ; \\
& \vartheta=\tan ^{-1}\left(\psi_{s \beta} / \psi_{s \alpha}\right),
\end{aligned}
$$

«Switching Table» - block that sets the value of the output voltage RV, based on the values of the Sector of stator flux and Line shaper blocks, according to the Table 1.

The selected RV corresponds to the switching function (see Table 2), which controls the switches of the voltage autonomous inverter feeding the IM.

Table 2. The correspondence of the RV to the IM phase and phase-to-phase voltages, and the

\begin{tabular}{|c|c|c|c|c|c|c|c|}
\hline \multirow[t]{2}{*}{ RV } & \multirow{2}{*}{$\begin{array}{l}\text { Switching } \\
\text { function }\end{array}$} & \multicolumn{3}{|c|}{ Phase voltages } & \multicolumn{3}{|c|}{$\begin{array}{c}\text { Phase-to-phase } \\
\text { voltages }\end{array}$} \\
\hline & & $\mathrm{U}_{\mathrm{A}}$ & $\mathrm{U}_{\mathrm{B}}$ & $\mathrm{U}_{\mathrm{C}}$ & $\mathrm{U}_{\mathrm{AB}}$ & $\mathrm{U}_{\mathrm{BC}}$ & $\mathrm{U}_{\mathrm{CA}}$ \\
\hline $\bar{U}_{0}(t)$ & $\mathrm{S}_{4}=\mathrm{S}_{6}=\mathrm{S}_{2}=1$ & 0 & 0 & 0 & 0 & 0 & 0 \\
\hline $\bar{U}_{1}(t)$ & $\mathrm{S}_{1}=\mathrm{S}_{6}=\mathrm{S}_{2}=1$ & $\frac{2 U_{d c}}{3}$ & $-\frac{U_{d c}}{3}$ & $-\frac{U_{d c}}{3}$ & $\mathrm{U}_{\mathrm{dc}}$ & 0 & $-\mathrm{U}_{\mathrm{dc}}$ \\
\hline $\bar{U}_{2}(t)$ & $\mathrm{S}_{1}=\mathrm{S}_{3}=\mathrm{S}_{2}=1$ & $\frac{U_{d c}}{3}$ & $\frac{U_{d c}}{3}$ & $-\frac{2 U_{d c}}{3}$ & 0 & $\mathrm{U}_{\mathrm{dc}}$ & $-\mathrm{U}_{\mathrm{dc}}$ \\
\hline $\bar{U}_{3}(t)$ & $\mathrm{S}_{4}=\mathrm{S}_{3}=\mathrm{S}_{2}=1$ & $-\frac{U_{d c}}{3}$ & $\frac{2 U_{d c}}{3}$ & $-\frac{U_{d c}}{3}$ & $-\mathrm{U}_{\mathrm{dc}}$ & $\mathrm{U}_{\mathrm{dc}}$ & 0 \\
\hline $\bar{U}_{4}(t)$ & $\mathrm{S}_{4}=\mathrm{S}_{3}=\mathrm{S}_{5}=1$ & $-\frac{2 U_{d c}}{3}$ & $\frac{U_{d c}}{3}$ & $\frac{U_{d c}}{3}$ & $-\mathrm{U}_{\mathrm{dc}}$ & 0 & $\mathrm{U}_{\mathrm{dc}}$ \\
\hline $\bar{U}_{5}(t)$ & $\mathrm{S}_{4}=\mathrm{S}_{6}=\mathrm{S}_{5}=1$ & $-\frac{U_{d c}}{3}$ & $-\frac{U_{d c}}{3}$ & $\frac{2 U_{d c}}{3}$ & 0 & $-\mathrm{U}_{\mathrm{dc}}$ & $\mathrm{U}_{\mathrm{dc}}$ \\
\hline $\bar{U}_{6}(t)$ & $\mathrm{S}_{1}=\mathrm{S}_{6}=\mathrm{S}_{5}=1$ & $\frac{U_{d c}}{3}$ & $\frac{2 U_{d c}}{3}$ & $\frac{U_{d c}}{3}$ & $\mathrm{U}_{\mathrm{dc}}$ & $-\mathrm{U}_{\mathrm{dc}}$ & 0 \\
\hline $\bar{U}_{7}(t)$ & $\mathrm{S}_{1}=\mathrm{S}_{3}=\mathrm{S}_{5}=1$ & 0 & 0 & 0 & 0 & 0 & 0 \\
\hline
\end{tabular}
switching functions as well.

\section{The Fuzzy DTC system}

Figure 4 presents the model of fuzzy DTC system created by Matlab.

The «Flux and Torque Comparators» block, which is part of the fuzzy DTC system, looks similar to the analogous block of the classical system (Figure 3), except for the absence of a RC inside. 


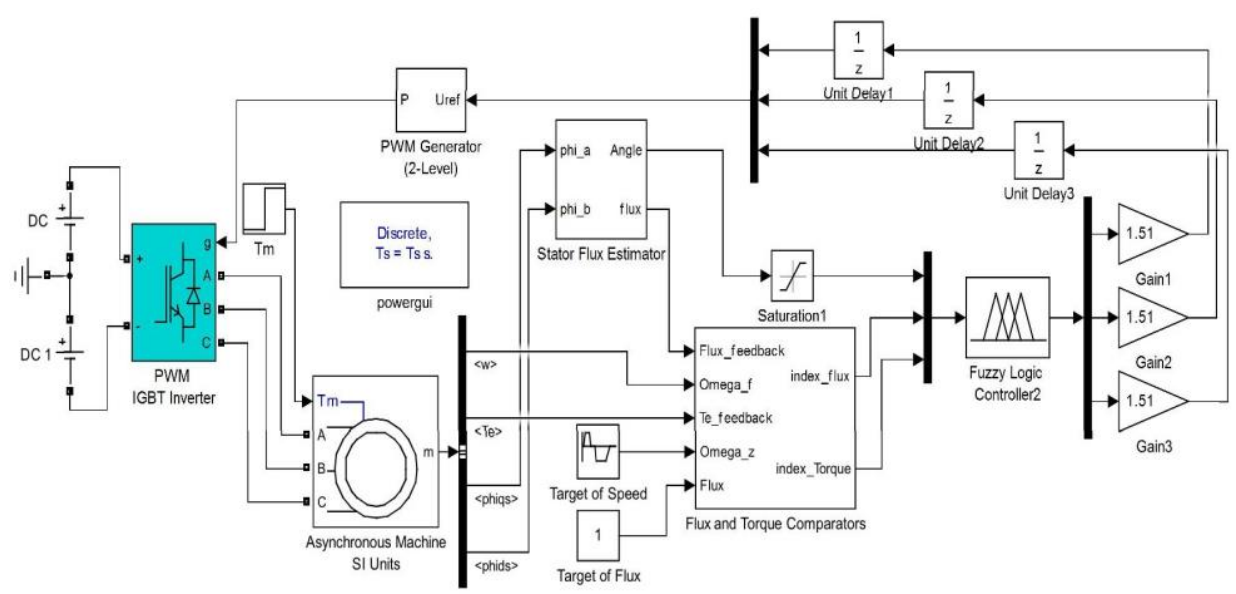

Fig. 4. Model of fuzzy DTC.

The «Fuzzy Logic Controller» block is a fuzzy controller (FC) based on the Sugeno algorithm with three input (Flux, Torque, Angle) and three output $\left(U_{a}, U_{b}, U_{c}\right)$ variables. Figure 5 shows the FC input variables. Variable Flux (Fig. 5.a) consists of two triangular terms 0 and 1. It corresponds to the two-position RC of Relay flux flow. Variable Torque (Fig. 5.b) is represented by three terms $(-1,0,1)$ given by Gauss functions. The variable performs the functions of a three-position RC (Relay_Torque). The third input variable is the Sector variable (Fig 5.c), replacing the work of the Sector of stator flux block. It consists of six triangular terms, each of which corresponds to its stator flux linkage sector. The detailed description of triangular and gaussian terms, as well as their implementation in Matlab, suggests in [9].

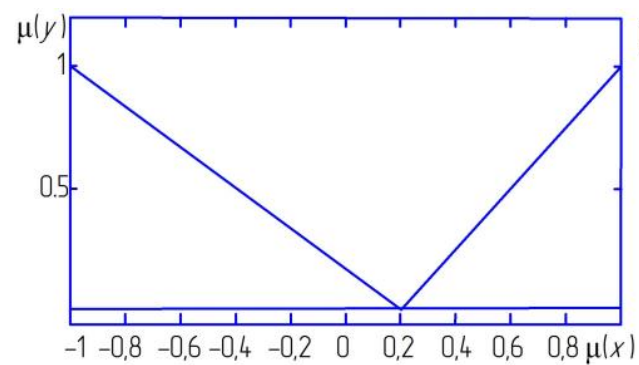

a)

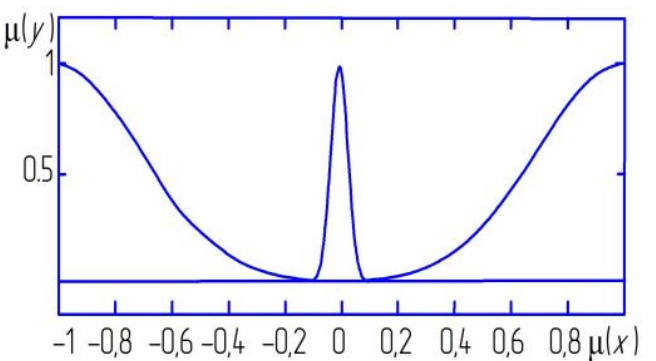

b)

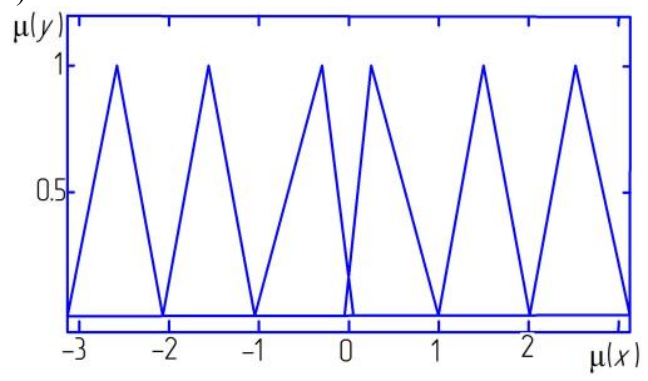

c)

Fig. 5. Input variables of FC: a) variable Flux; b) variable Torque; c) variable Sector.

Sugeno knowledge base is analogous to the knowledge base of Mamdani except for the rules conclusions, which defines not by fuzzy terms, but by a linear function from the 
inputs [10]. The output variables of our FC are the coefficients by which it is necessary to multiply the voltage in the DC link of the voltage autonomous inverter in order to obtain the values of the phase voltages. For each of the three phases there are five such coefficients, they are $2 / 3,1 / 3,0,-2 / 3,-1 / 3$. The FC knowledge base forms up according to the Table 1. The rules in Sugeno knowledge base are switches from one linear law "inputsoutputs" to another, also linear. The boundaries of the subregions are diffuse, therefore, several linear laws can be fulfilled simultaneously, but with different degrees [11]. The linguistic expression (rule) describing the logic of the fuzzy DTC system operation with positive flux and torque, close to the nominal values, and also for the vector of flux linkage, located in the first sector, looks like:

If (Sector is 1$)$ and (Flux is 1$)$ and (Torque is 1$)$ then $\left(U_{a}\right.$ is $\left.1 / 3\right)\left(U_{b}\right.$ is $\left.1 / 3\right)\left(U_{c}\right.$ is $\left.-2 / 3\right)$.

The method PROD (product) is selected as the method of implementing the logical operation and. To find the resulting value of output variables, the WTAVER (weighted average) defuzzification method is used.

At the output of the fuzzy controller are proportional links designed to normalize the signals to the scale [0..1], which allows you to use signals as a reference for PWM. In our opinion, the available RV from the Table 1, as shown in [10], is not enough to realize the full potential of using fuzzy logic, since rounding the decimal values of the FC output signals to an integer nullifies the useful effect of using FC and makes its work similar to the classical DTC.

\section{Simulation and results analysis}

Aiming blending functions graphs the computational experiments were realized on three DTC systems types listed below:

1) the classical DTC system with output coordinate, which is the switching function controlling the unlocking and locking of IGBT switches of the inverter;

2) the DTC system operating according to the laws of the classical DTC, except for the output coordinate, which is the PWM voltage reference;

3) fuzzy DTC system.

Evaluating the harmonic composition of the IM phase-to-phase feeding voltage of IM with DTC allowed identifying a number of high frequencies associated with controllers switching. Limited to the consideration of the most pronounced components of the spectrum with the value of harmonics not less than $20 \%$ of the main, we found that the central frequency for them (found as the average mean of the considered frequencies) was approximately $4650 \mathrm{~Hz}$. For adequate consideration with the rest of the methods, choose the frequency value as the PWM carrier frequency. In our opinion, for a more objective study of how the control method choice affects the dynamics of the torque, it is necessary to consider these processes at low rotation speeds. We choose follows: $1 \mathrm{rad} / \mathrm{s} ; 5 \mathrm{rad} / \mathrm{s} ; 10$ $\mathrm{rad} / \mathrm{s}$, since significant oscillations of electromagnetic torque in such conditions can lead to uneven rotation of the engine's rotor, which is unacceptable for many mechanisms and technological processes.

The results of determining the total coefficients of the torque harmonic distortion (THD), the stator phase current, and the phase-to-phase voltage for the three models listed above are given at the Table 3. After analyzing them, we can conclude that the fuzzy DTC shows the best results on the harmonic compositions for the torque and phase-to-phase voltage at medium and higher rotational frequencies from the range under consideration, and the classic DTC - at low frequencies. DTC with PWM is the worst case at all speeds. As to the THD of the current, the fuzzy DTC is the best at low and medium speeds, and the DTC with PWM - at a higher rotation frequency. The classical DTC does not stand competition for this indicator at all speeds, which can be interpreted as the lowest efficiency 
rate of the considered methods above relates to it. We also made the torque pulse coefficients calculation for the three models with different target of speeds.

Table 3. The results of THD analysis.

\begin{tabular}{|c|c|c|c|c|c|}
\hline $\begin{array}{l}\text { Method of } \\
\text { control }\end{array}$ & $\begin{array}{c}\text { Target of } \\
\text { speed }\end{array}$ & $\begin{array}{l}\text { THD of } \\
\text { Torque }\end{array}$ & $\begin{array}{l}\text { THD of } \\
\text { current }\end{array}$ & THD of voltage & $\begin{array}{c}\text { Freq. } \\
\text { of } \\
\text { PWM }\end{array}$ \\
\hline DTC & $1 \mathrm{rad} / \mathrm{s}$ & 1.47 & 6.84 & 224.46 & \multirow{3}{*}{2346} \\
\hline $\begin{array}{l}\text { DTC with } \\
\text { PWM }\end{array}$ & $1 \mathrm{rad} / \mathrm{s}$ & 2.74 & 3.06 & 675.71 & \\
\hline Fuzzy DTC & $1 \mathrm{rad} / \mathrm{s}$ & 1.8 & 1.96 & 247.34 & \\
\hline DTC & $5 \mathrm{rad} / \mathrm{s}$ & 1.44 & 13.28 & 156.77 & \multirow{3}{*}{3796} \\
\hline $\begin{array}{l}\text { DTC with } \\
\text { PWM }\end{array}$ & $5 \mathrm{rad} / \mathrm{s}$ & 3.26 & 3.26 & 496.96 & \\
\hline Fuzzy DTC & $5 \mathrm{rad} / \mathrm{s}$ & 1.35 & 3.24 & 148.1 & \\
\hline DTC & $10 \mathrm{rad} / \mathrm{s}$ & 1.44 & 16.81 & 136.17 & \multirow{3}{*}{4650} \\
\hline $\begin{array}{l}\text { DTC with } \\
\text { PWM }\end{array}$ & $10 \mathrm{rad} / \mathrm{s}$ & 2.84 & 2.96 & 342.68 & \\
\hline Fuzzy DTC & $10 \mathrm{rad} / \mathrm{s}$ & 1.32 & 16.22 & 123.66 & \\
\hline
\end{tabular}

The speed transient processes at $5 \mathrm{rad} / \mathrm{s}$ and $10 \mathrm{rad} / \mathrm{s}$ look similarly for all three systems. Let's take a closer look at transient processes when setting the speed to $1 \mathrm{rad} / \mathrm{s}$. As shown in figure $6 \mathrm{a}$, the flow of the perturbing effect at the moment which value is equal to the nominal moment, in the case of $1^{\text {st }}$ control method leads to the most significant drop in the rotation speed of the rotor. Transient processes for $2^{\text {nd }}$ and $3^{\text {rd }}$ control methods are almost identical (Fig. 6b, 6c).
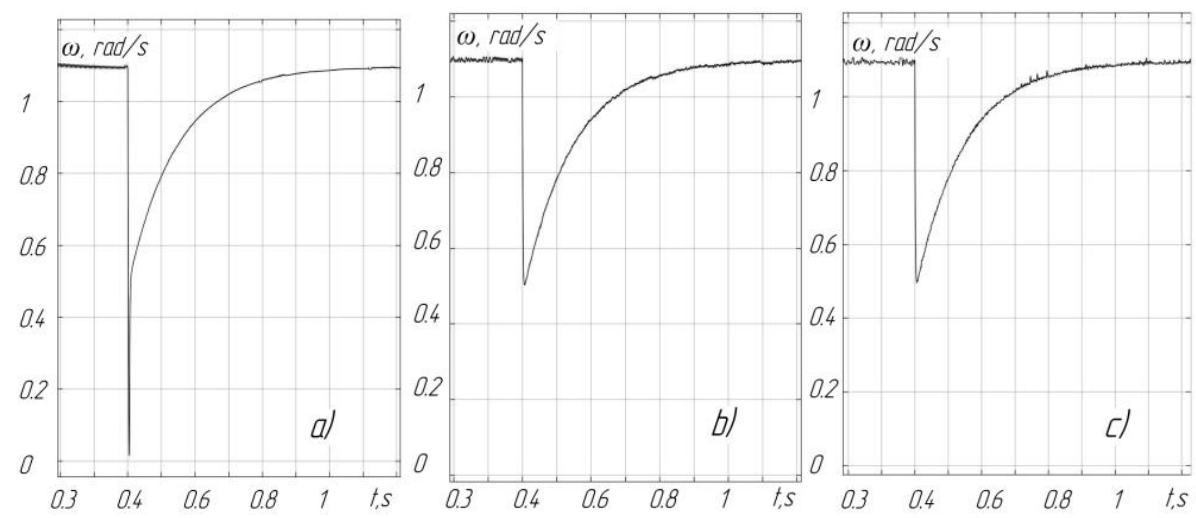

Fig. 6. The reaction of the rotation speed to the perturbing effect with respect to the load torque when the desired speed is set at 0.1 from the nominal: a) Classic DTC; b) DTC with PWM; c) Fuzzy DTC. 


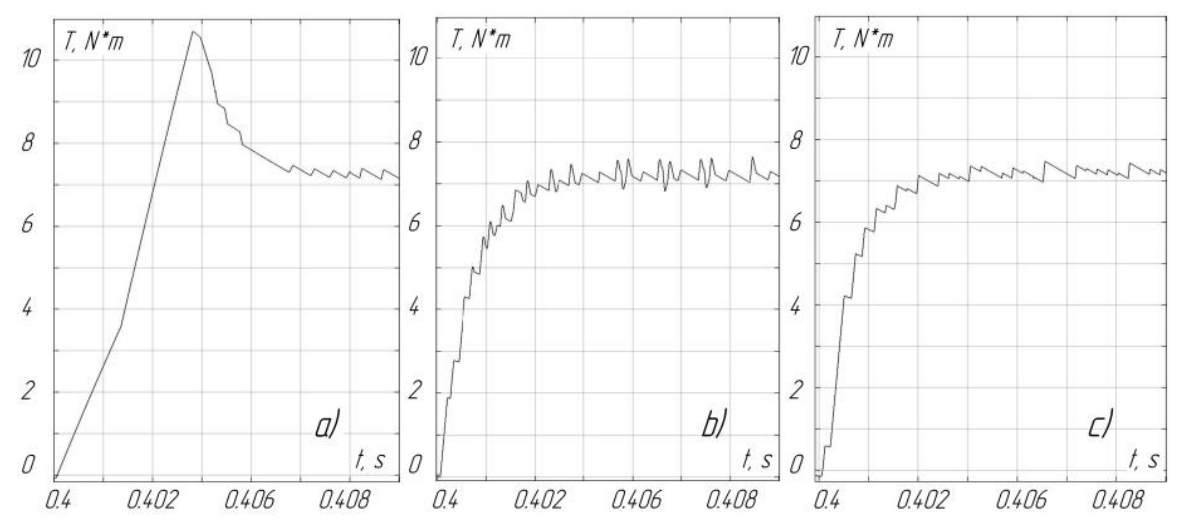

Fig. 7. Dynamics of the torque: a) Classic DTC; b) DTC with PWM; c) Fuzzy DTC.

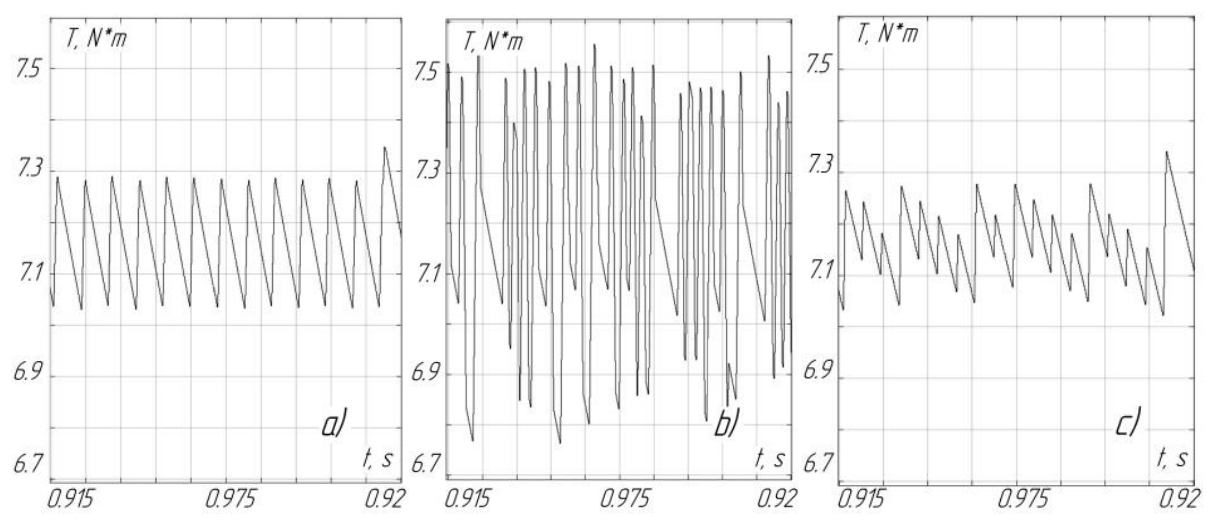

Fig. 8. The graph of the torque in steady state: a) Classic DTC; b)DTC with PWM; c) Fuzzy DTC.

\section{Conclusions}

Based on the results of the conducted studies, it can be concluded that the use of the mathematical apparatus of fuzzy logic in DTC systems is justified, since this allows achieving a close, and often better harmonic composition with respect to voltage, current and torque comparing to the classical DTC. Also, the torque dynamics in case of fuzzy DTC looks preferable to the same one of classic DTC. It should be noted that for the transition from the classical method to fuzzy, it is enough to change only the control algorithm, without the need for structural changes, which makes this transition attractive in terms of price-quality ratio.

\section{References}

1. V.M. Perelmutor, Direct control of the torque and current of the AC motor, 210 (2004)

2. G.G. Sokolovsky, Electric drives of AC with frequency control, 272 (2006)

3. I. Takahashi, IEEE Trans., 5, 820-827 (1986) 
4. P.G. Kolpakhchyan, All-Rus. Sci. Res. and D/. and D. Ins. of Elec. Loc. Buil., 1, 108120 (2007)

5. Y. Liu, X. Wang, Y. Xing, Engineering Review , 33, 203-209 (2013)

6. F. Korkmaz, I. Topaloglu, H. Mamur, Int. Jour. on Soft Com., 5/6, 31-40 (2013)

7. S. Karpe, S.A. Deokar, A.M. Dixit, Jour. of Elec. Sys. and Infor. 4, 225-242 (2017)

8. D.Y. Karandeyev, E.A. Engel, Internet-journal "Naukovedenie", 5 (2015)

9. D.V. Olkhovatov, Sim: Theory, methods and tools, 345-353 (2016)

10. S. D. Shtovba, Design of fuzzy systems by means of MATLAB, 288 (2007)

11. M.G. Danilova, S.Yu. Chernyshov, E.N. Sidorov, M.S. Osnovin, Engineering Bulletin of the Don, Simulation of an asynchronous drive with fuzzy direct torque control in Simulink, 3(2014) 